\title{
Subjective Response to Environmental Noise of Locomotives in the UK
}

\author{
A.E.J. Hardy and R.R.K. Jones \\ AEA Technology Rail, PO Box 2, London Rd, Derby, DE24 8YB, UK
}

(Received 16 November 1999; accepted 28 September 2000)

\begin{abstract}
The environmental noise characteristics of locomotives are significantly different from those of railway coaches, particularly at low speeds. This difference is primarily due to the presence of exhaust and engine carcass noise in the case of diesel locomotives, and cooling fan noise for both diesel and electric locomotives. As a result, simple indices alone, such as the A-weighted sound level, are not always adequate for the quantification of noise from these vehicles, either for the purposes of specification or for environmental impact assessment. The paper presents the results of listening tests for locomotives, and discusses potential indices for the quantification of subjective response to them. Reference is made to a diesel locomotive that is known to be subjectively quiet due to careful design. The specification approach adopted for this locomotive is discussed, together with improvements that might be made to similar specifications in the future.
\end{abstract}

\section{INTRODUCTION}

The use of the A-weighted sound level $\left(L_{A}\right)$ in the prediction of environmental impact of noise can be viewed as a convenient compromise, particularly from the point of view of legislation and standardisation. However, it is known that there are certain types of noise source with characteristics that are not amenable to such straightforward quantification when their impact on the community is to be assessed. One such source is the railway locomotive.

Wheel/rail interaction is the dominant source of wayside noise from trains travelling at speeds from around $70 \mathrm{~km} / \mathrm{h}$ to $300 \mathrm{~km} / \mathrm{h}$. This rolling noise is characterised by spectra whose peaks lie within the range from approximately $500 \mathrm{~Hz}$ to $4000 \mathrm{~Hz}$. In this case, the A-weighted sound level is found to be an adequate indicator of human perception. However, locomotives hauling passenger coaches or freight wagons can be a major contributor to the noise signature of trains operating at lower speeds or when stationary. For diesel locomotives, the major sources are from the engine exhaust, engine and traction motor cooling fans, and the engine carcass, and cover a broad frequency range. For electric locomotives, cooling fans for transformers and traction motors are the dominant sources, and here the noise can have strong tonal elements combined with broadband noise.

Experience in the United Kingdom indicates that locomotives, particularly those that are diesel-engined, can be a greater cause for public complaint than their A-weighted sound levels alone would suggest. This problem was taken into account by British Rail (BR) in the 1980s when specifications were formulated for proposed new locomotives. The aim was to specify allowable environmental noise using a measure that both reflected public response and encouraged manufacturers to devise noise-control techniques leading to a more acceptable characteristic in terms of spectrum and level.

There was little published work on this subject at that time (or subsequently), but there had been one comprehensive study at the Institute of Sound and Vibration Research reported by Fields. ${ }^{1}$ This study had shown that adverse public reaction to a given level of railway noise, measured in terms of 24 hour $L_{e q} \mathrm{~dB}(\mathrm{~A})$, is generally greater for routes with diesel traction than for those with overhead-electric traction. The British Rail database was therefore used to provide information on the differences between the typical characteristics of diesel traction and those of electric traction. This examination of the data led to the conclusion that the wayside noise from locomotives could be better quantified, in terms of public reaction, by defining both the maximum A-weighted sound level and the difference between the $\mathrm{C}$-weighted and A-weighted sound levels $\left(L_{C}-L_{A}\right)$. If this difference were set at $7 \mathrm{~dB}$ or less, a value that was known to be achievable with careful acoustical design, it was considered that the A-weighted sound level could then be used as a unified index for these two forms of traction. As a result, external starting noise and idling noise specifications for British Rail locomotives procured during the late 1980s and early 1990 s, prior to privatisation, were written in terms of the maximum allowable sound level in $\mathrm{dB}(\mathrm{A})$ and a maximum allowable value for the difference between the $\mathrm{C}$-weighted and the A-weighted sound levels of $7 \mathrm{~dB}$.

This approach led to a design of diesel locomotive that was significantly more environmentally acceptable than previous "classic" British Rail diesel locomotives.

Figure 1 shows a typical spectrum of starting noise measured $7.5 \mathrm{~m}$ from this 'Last generation BR' locomotive, compared with that of a 'Classic BR' locomotive that is 30 years older but still in revenue-earning service.

It can be seen from Fig. 1 that the spectral characteristics of the two locomotives are very similar at frequencies of $250 \mathrm{~Hz}$ and above, reflected in the similarity of their A-weighted levels. However, experience has shown that the 'Last generation' locomotive is subjectively much more environmentally acceptable, as a result of the reduced levels of low frequency sound. This environmental advantage was as a direct consequence of the locomotive being built to a specification requiring $L_{C}-L_{A}$ to be $7 \mathrm{~dB}$ or less, and was achieved primarily by careful design of the engine exhaust silencer and sensible air management in the cooling system.

Although the use of $L_{C}-L_{A}$ as an indicator of the acceptability of locomotive noise was a comparatively simple approach, it provided a technique that was easy both for all in- 